\title{
Sakubitril/valsartan'ın doz titrasyonu hangi hastada nasıl yapılmalı?
}

\author{
Dr. Zeki Öngen, 도. Dr. Eser Durmaz \\ İstanbul Üniversitesi-Cerrahpaşa, Cerrahpaşa Tıp Fakültesi, Kardiyoloji Anabilim Dalı, İstanbul
}

Düşük ejeksiyon fraksiyonlu kalp yetersizlikli (DEFKY) olgularda gerek tüm nedenli gerekse kalp damar sistemi kaynaklı ölümleri önlemede ve hastaneye yatışları azaltmada etkili olan sakubitril/valsartanın PARADIGM-HF çalışmasında sınanan hedef dozu günde 2 kez verilen 97/103 mg'dır. ${ }^{[1]}$ Söz konusu çalışmada da olduğu gibi tedaviye hedef dozla başlama yerine daha düşük bir dozla başlayıp 2-4 hafta sonra doz artırımında bulunma yöntemi benimsenmiştir. İlacın güncel kalp yetersizliği kılavuzlarına sınıf I, B düzeyi kanıtla girmesini sağlayan bu çalışmada etkili dozlarda anjiyotensin dönüştürücü enzim inhibitörü (ACE-İ) (enalaprilin $10 \mathrm{mg} /$ gün üstü dozuna eş değer ACE-İ) ya da anjiyotensin reseptör blokeri (ARB) (valsartanın $160 \mathrm{mg} /$ gün üstü dozuna eş değer ARB) kullanmakta olan hastalar, randomize edilmeden önceki bir giriş döneminde günde $2 \mathrm{kez} 49 / 51 \mathrm{mg}$ sakubitril/valsartan ile tedaviye başlamış sonra hedef doza ulaşılmıştır. ${ }^{[2-4]} \mathrm{Bu}$ verilerden yola çıkarak iki doz ile uygulama yapabilecek iken şu anda elimizin altında niye üç doz seçeneği var sorusu gündeme gelebilir. Sorunun yanıtı açıtır. Randomize kontrollü çalışmalar dikkatle okunduğunda hep çalışma dışında tutma ölçütleri içerdikleri görülür. Oysa ki bizim günlük uygulamada hastaları uygulama dışı tutma şansımız yoktur. Yapılacak şey çalışma sonuçlarını bizim karşılaştı̆̆ımız hastalara uyarlamaktır. Bu genel ilkeyi konumuza özelleştirirsek PARADIGM-HF çalışması dışında tutulan ancak günlük uygulamada sık karşılaşacağımız başlıca üç hasta grubu için çözüm bulmak durumundayız. Bu hastalar yukarıda sözü edilen etkili dozların altında ACE-İ ya da ARB kullananlar, hiç renin-anjiyotensin-aldosteron antagonisti kullanmayanlar ve eGFR'si $30 \mathrm{ml} / \mathrm{d}$ altında olanlardır. Bunları da sakubitril/valsartanın olumlu etkilerinden yararlandırmak amacı ile titrasyona üçüncü doz olan 24/26 mg ile başlama gereği ortaya çıkmıştır.

\section{Hangi hastada 24/26 mg sakubitril/ valsartan başlangıç dozu olarak seçilmeli?}

$\mathrm{Bu}$ bölümü söz konusu dozun PARADIGM-HF çalışmasında sınanmadığını akılda tutarak okumak gerekir. Bir başka deyişle burada çalışma dışında tutulmasına karşın sık karşılaştığımız özelliği olan kalp yetersizlikli hastalarda sakubitril/valsartan başlangıç dozu tartışılacaktır. Bunlar:

- Günlük ACE-İ dozu enalapril $\leq 10 \mathrm{mg}$ ya da eş değeri olanlar.

- Günlük ARB dozu valsartan $\leq 160$ mg ya da eş değeri olanlar.

- Tedavilerinde ACE-İ/ARB bulunmayanlar.

- eGFR $<30 \mathrm{ml} / \mathrm{d} / 1.73 \mathrm{~m}^{2}$ olanlar.

- Orta derecede (Child-Pugh sinıf B) karaciğer yetersizliği olanlar.

- Yaş $\geq 75$ olanlar. ${ }^{[5]}$

Yukarıda sözü edilen hasta gruplarında sakubitril/ valsartanın en düşük dozu günde $2 \mathrm{kez}$ verilerek tedaviye başlansa da amaç en üst doza çıkmak olmalıdır. Bunun için hastanın kan basıncı yanıtı, böbrek işlevi ve K düzeyi izlenmeli, olumsuz bir durum saptanmadıkça 2-4 hafta aralıklarla doz önce 49/51 mg x2/gün ve bundan 2-4 hafta sonra da 97/103 mgx2/ güne çıkılmalıdır. Kan basıncındaki düşme (sistolik $\leq 90 \mathrm{mmHg}$ ) ya da eGFR'deki azalma ( $\geq \% 30)$ hedef doza varılmasını engelliyorsa hastanın bu bozukluklar olmadan yaşamını sürdürebildiği en yüksek doz ile tedaviye devam edilmelidir. ${ }^{[5]}$ Sakubitril/valsartan tedavisi altında ortaya çıkan kan basıncı düşüşü ya da böbrek işlev bozukluğu ile nasıl başa çıkılacağı başka bölümlerin konusu olduğu için burada değinilmeyecektir ancak hipo/övolemik bir hastada diüretik dozlarının azaltılmasının sakubitril/valsartan doz artışına yardımcı olacağını vurgulamakta yarar vardır. ${ }^{[5,6]}$

Günlük yaşantıda ilacın düşük dozları ile tedaviye başlama gereğinin hiç de seyrek olmadığı konuyu araştıran gözlemsel çalışmalardan anlaşılmaktadır. Yayınlanan verilere göre hastaların \%51-68'inde 24/26 mg x2/gün ile tedaviye başlanmaktadır. ${ }^{[7-9]}$ Ancak bu durum hedef doza ya da hastanın dayanabildiği 


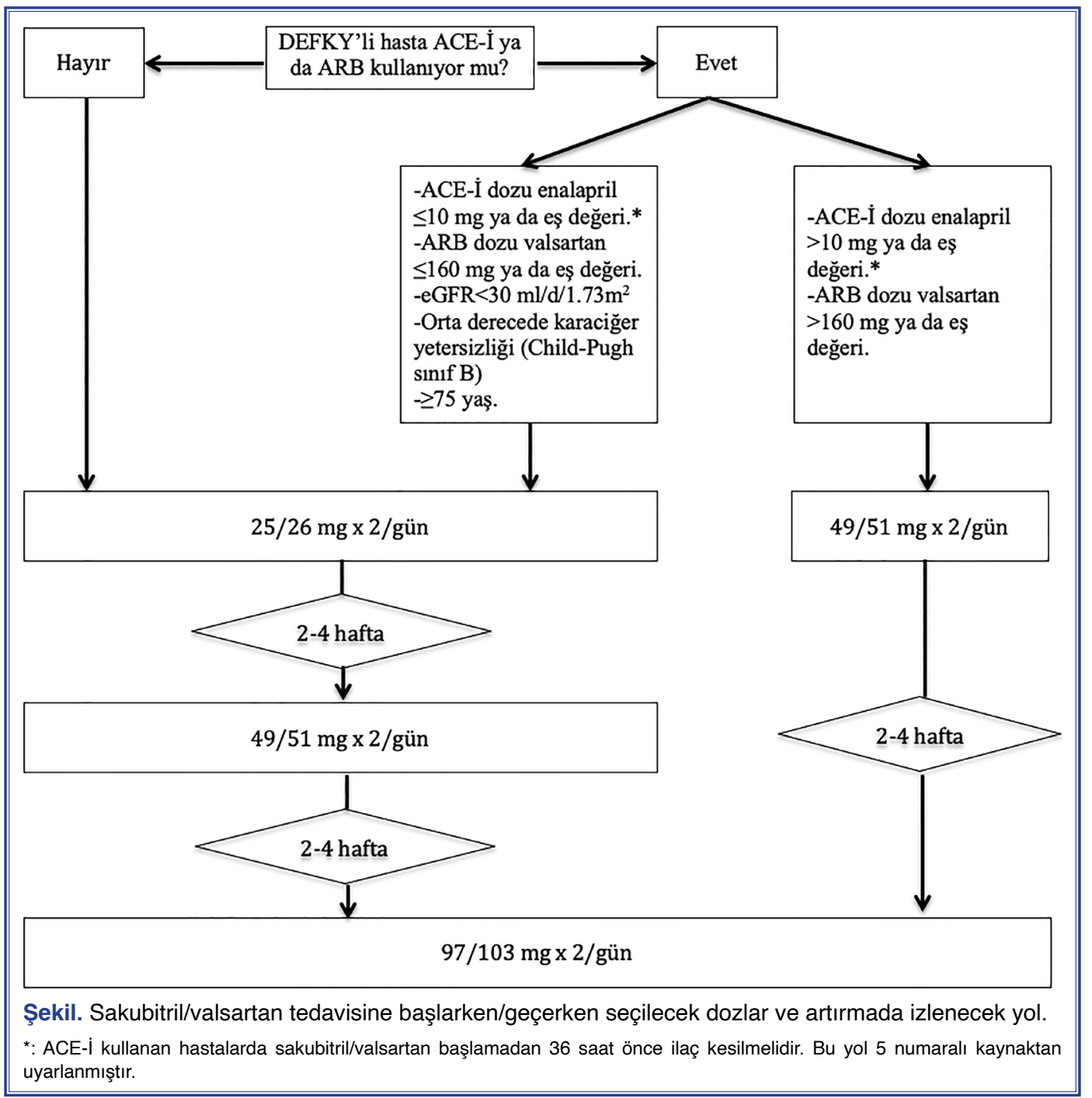

en üst doza çıkılması için çaba gösterilmesine engel değildir, olmamalıdır.

\section{Hangi hastada 49/51 mg sakubitril/ valsartan başlangıç dozu olarak seçilmeli?}

Sakubitril/valsartanın günde $2 \mathrm{kez}$ verilen 49/51 mg'lık dozu PARADIGM-HF çalışmasında başlangıç dozu olarak sınanmıştır. ${ }^{[1,2]}$ Tedavilerinde enalapril $>10 \mathrm{mg}$ ya da eş değeri ACE-İ veya valsartan $>160$ mg ya da eş değeri ARB kullanan ve NYHA II-IV düzeyinde semptom tanımlayan DEFKY'li hastalarda sakubitril/valsartan tedavisine bu dozla geçilmelidir.

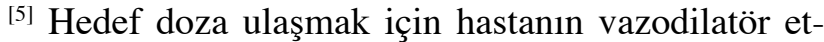
kiye uyumu 2-4 hafta beklendikten sonra doz artımı yapılır. Burada da kan basıncı düzeyi ve böbrek işlevi izlenmesi gereken parametrelerdir.

Yapılan gözlemsel çalışmalarda bu grubun, sakubitril/valsartan tedavisi adayi olan DEFKY'li hastala- rın \%30.5-38'ni oluşturduğu bildirilmiştir. ${ }^{[7-9]}$ Hasta özellikleri nedeni ile tedaviye bu dozla başlanabilen hastaların hedef doza ulaşma oranı önceki doza göre daha yüksektir. ${ }^{[9]}$

\section{Hangi hastada 97/103 mg sakubitril/ valsartan başlangıç dozu olarak seçilmeli?}

Başlangıç dozu olarak çalışmada sınanmamıştır ve ilgili kılavuzlarda da başlangıç için önerilmez. Ancak günlük yaşamda olguların \%2-11'inin tedavisine bu dozla başlandığ 1 bildirilmektedir. ${ }^{[7-9]} \mathrm{Te}-$ davilerinde $20 \mathrm{mg}$ enalapril (ya da eşdeğeri ACE-İ) veya $32 \mathrm{mg}$ kandesartan (ya da eşdeğeri $\mathrm{ARB}$ ) olan ve sistolik kan basınc1 120 mmHg'nın üzerinde bulunan hastalarda bu dozla başlamanın güvenli olduğunu gösteren bir çalışma vardır. ${ }^{[10]} \mathrm{Bu}$ doz, k1lavuzlar tarafından önerilmemesi nedeni ile tedavi algoritmasında yer almayacaktır. 


\section{Kaynaklar}

1. McMurray JJ, Packer M, Desai AS, Gong J, Lefkowitz MP, Rizkala AR, et al. Angiotensin-neprilysin inhibition versus enalapril in heart failure. N Engl J Med 2014;371:993-1004.

2. McMurray JJ, Packer M, Desai AS, Gong J, Lefkowitz MP, Rizkala $\mathrm{AR}$, et al. Dual angiotensin receptor and neprilysin inhibition as an alternative to angiotensin-converting enzyme inhibition in patients with chronic systolic heart failure: rationale for and design of the Prospective comparison of ARNI with ACEI to Determine Impact on Global Mortality and morbidity in Heart Failure trial (PARADIGM-HF). Eur J Heart Fail 2013;15:1062-73.

3. Yancy CW, Jessup M, Bozkurt B, Butler J, Casey DE Jr, Colvin MM, et al. 2017 ACC/AHA/HFSA Focused Update of the 2013 ACCF/ AHA Guideline for the Management of Heart Failure: A Report of the American College of Cardiology/American Heart Association Task Force on Clinical Practice Guidelines and the Heart Failure Society of America. J Am Coll Cardiol 2017;70:776-803.

4. Ponikowski P, Voors AA, Anker SD, Bueno H, Cleland JGF, Coats AJS, et al. 2016 ESC Guidelines for the diagnosis and treatment of acute and chronic heart failure: The Task Force for the diagnosis and treatment of acute and chronic heart failure of the European Society of Cardiology (ESC)Developed with the special contribution of the Heart Failure Association (HFA) of the ESC. Eur Heart J 2016;37:2129-200.
5. Yancy CW, Januzzi JL Jr, Allen LA, Butler J, Davis LL, Fonarow GC, et al. 2017 ACC Expert Consensus Decision Pathway for Optimization of Heart Failure Treatment: Answers to 10 Pivotal Issues About Heart Failure With Reduced Ejection Fraction: A Report of the American College of Cardiology Task Force on Expert Consensus Decision Pathways. J Am Coll Cardiol 2018;71:201-30.

6. Pharithi RB, Ferre-Vallverdu M, Maisel AS, O'Connell E, Walshe M, Sweeney C, et al. Sacubitril-Valsartan in a routine community population: attention to volume status critical to achieving target dose. ESC Heart Fail 2020;7:158-66.

7. Yandrapalli S, Andries G, Biswas M, Khera S. Profile of sacubitril/ valsartan in the treatment of heart failure: patient selection and perspectives. Vasc Health Risk Manag 2017;13:369-82.

8. Martens P, Beliën H, Dupont M, Mullens W. Insights into implementation of sacubitril/valsartan into clinical practice. ESC Heart Fail 2018;5:275-83.

9. Sangaralingham LR, Sangaralingham SJ, Shah ND, Yao X, Dunlay SM. Adoption of Sacubitril/Valsartan for the Management of Patients With Heart Failure. Circ Heart Fail 2018;11:e004302.

10. Norberg H, Bergdahl E, Lindmark K. Safety and Tolerability of Initiating Maximum-Dose Sacubitril-Valsartan in Patients on Target Dose Renin-Angiotensin System Inhibitors. Cardiovasc Ther 2019;2019:6745074. 